\title{
Health-Related Quality of Life in Patients with Type-2 Diabetes Mellitus
}

\author{
Anitha.P, Viswanathan.S, Saritha K.Narayanan and A.John William Felix
}

\begin{abstract}
Aim: The aim of the study was to find out the quality of life in patients with type- 2 diabetes mellitus. Material and Method: A descriptive survey design was conducted among 100 Type-2 diabetic patients attending Rajah Muthiah Medical College and Hospital, Chidambaram Tamilnadu for a period of one year. Information regarding socio-demographic characteristics like age, gender, occupation, personal history, education, etc. was collected in pretested proforma by interview method. Assessment of QOL of life was done using the Quality Of Life Instrument for Indian diabetic [QOLID] questionnaire. The data entry and statistical analysis were done using Microsoft Excel and SPS22 version. Data collected from the patient in QOL were analyzed using descriptive statistics. Results: Among 100 study participants majority, 45\% belonged to age group of 51-60years, $63 \%$ were female, $49 \%$ belonged to lower socio-economic class according to BG Prasad classification, 82 percent were married,49\%were overweight, $51 \%$ were having family history of diabetes, 50\%were having visual impairment, 92\% were on oral hypoglycemic medication the mean total of QOLID questioner score in physical health was 19.0, physical endurance 18.33, general health 7.09, treatment satisfaction 12.4, symptom bothered 10.7, financial worries 13.44 , mental health 14.5 and diet satisfaction 8.44 . However, the study result shows that the physical component was more affected in diabetic patients. Conclusion: This study observed Physical component was affected in diabetic persons. The study concluded that patients with Type-2 diabetes mellitus had relatively impact in health-related quality of life (PH, PE \& GH) domains and unsubstantial in diabetes-specific quality of life (SB, TS FW, MH\&DS) domains.
\end{abstract}

\section{Anitha.P}

Tutor in Physiotherapy

Department Physical Medicine and Rehabilitation

Rajah Muthiah Medical College and Hospital

Annamalai University, Annamalai Nagar (Tamilnadu) India

E mail: cdm_visu@yahoo.com

Viswanathan.S

Lecturer in Physiotherapy

Department Physical Medicine and Rehabilitation

Rajah Muthiah Medical College and Hospital

Annamalai University,Annamalai Nagar (Tamilnadu) India

Saritha K.Narayanan

Associate Professor

Department of Medicine

Rajah Muthiah Medical College and Hospital

Annamalai University,Annamalai Nagar (Tamilnadu) India

A.John William Felix

Reader

Department of Community Medicine

Rajah Muthiah Medical College and Hospital

Annamalai University, Annamalai Nagar (Tamilnadu) India
Key Words: Diabetes Mellitus, Quality of life, Quality Of Life Instrument for Indian Diabetes

DOI: $10.18376 / j e s p / 2019 / v 15 / i 1 / 111320$ 


\section{Journal of Exercise Science \& Physiotherapy Vol. 15 No. 1 (January to June) 2019 \\ ISSN: 0973-2020 (Print) I I OR Impact Factor $=6.502 \quad$ ISSN: 2454-6089 (Online)}

\section{Introduction}

"Diabetes cannot be cured It can only be controlled." In the twenty-first century, we see more globalization and industrialization, longer life spans, and changes in lifestyles worldwide. Consequences of these changes will be a shift in the pattern of disease, with chronic diseases such as diabetes becoming more prevalent (Narayanan et. al., 2000). India is regarded as the "Diabetes Capital" of the world owing to the existence of the largest number of people with diabetes in this country (World Health Organization 2014 and International Diabetes Federation 2009). The International Diabetes Federation (IDF) indicates that the number of people living with diabetes globally is expected to rise from 366 million in 2011 to 552 million by 2030 (Wild et. al., 2004). Diabetes is a serious, chronic disease characterized by chronic elevation of blood glucose and disturbance of carbohydrate, fat and protein metabolism that occur either when the pancreas does not produce enough insulin or when the body cannot effectively use the insulin it produce (World Health Organization 1999). Type-2 diabetes is the predominant form of diabetes in worldwide accounting for $90 \%$ of cases globally. In Asia, the rise in prevalence of type- 2 diabetes is even more distressing with increased occurrence of young adults (Zimmet et. al., 2001 and King et. al., 1998). The so-called South Asian or "Asian Indian" Phenotype make this ethnic group more susceptible to both type -2 diabetes and premature coronary artery disease, compared to white Caucasians. This phenotype is characterized by increased insulin resistance; high diabetes rates, despite lower generalized obesity; central adiposity; and dyslipidemia, with raised serum triglycerides and low levels of high-density lipoprotein (HDL) cholesterol. The current diabetes epidemic is fuelled predominantly by lifestyle, which related to environmental factors. The two most important of these are unhealthy diet and physical inactivity (Unnikrishnan and Anjana 2014). Several studies reported that type- 2 diabetes is caused by genetic (multiple gene involvement) and environmental factors (obesity, overeating, lack of exercise, stress, and aging (Wang et. al., 2017; Kohai 2010; Olokoba and Obateru 2012; Hub 2003). Health-related quality of life (HRQOL) is now recognized as being inclusive terms that assess both selves -reported mental and physical functioning of an individual. HRQOL is defined as the physical, psychological, and social domains of health, seen as distinct areas that are influenced by a person's experience, beliefs, expectations and perceptions (Testa and Simonson 1996).

Quality of Life issues in Diabetes Mellitus- People with diabetes often challenged by their disease and its day-to-day management demands and these demands are substantial. Patients must deal with their diabetes all day, every day, making countless decisions in an often futile effort to approximate the non-diabetic metabolic state. Diabetes therapy, such as taking insulin can substantially affect the quality of life either positively, by reducing symptoms of high blood sugar, for instance, or negatively, by increasing symptoms of low blood sugar, for example. The psychosocial toll of living with diabetes is often a heavy one, and this toll can often, in turn, affect self-care behavior and ultimately, long term glycemic control, the risk of developing long-term complications and quality of life (Richard and Mark 1999). Several demographic and psychological factor which have effects on QOL are age, gender, complications treatment and duration of diabetes (Wandell 2005). In the concept, a psychological, several have revealed that social support, self-care activities, knowledge about diabetes, sadness, worries, and stress were related to QOL (Chyun et. al., 2006; Tang et. al., 2006). The complication of diabetes includes microvascular (nephropathy, retinopathy, and neuropathy) and macrovascular (cardiovascular disease, cerebrovascular accident, diabetic foot) with comorbidities it leads to a sustained decrease inpatients QOL. Hence this study was planned with an objective to determine the quality of life in patients with type-2 diabetes mellitus. 


\section{Journal of Exercise Science \& Physiotherapy Vol. 15 No. 1 (January to June) 2019 \\ ISSN: 0973-2020 (Print) I I OR Impact Factor $=6.502 \quad$ ISSN: 2454-6089 (Online)}

\section{Material and Method}

Study design was descriptive survey. Study population was Patients diagnosed with type 2diabetes mellitus (both gender, age group above 30 years, duration of diabetes for more than one year). Sample size was 100 subjects and study was conducted at Department of Physical Medicine and Rehabilitation \& Department of Medicine, Rajah Muthiah Medical College and Hospital, Annamalai University.This descriptive survey study was approved by the Institution Human Ethics Committee with reference number IHEC /0320. provided they are written informed participating in was preserved throughout the study. One hundred $(\mathrm{N}=100)$ Type -2 diabetics from Department of Physical Medicine \& Rehabilitation and Medicine OPD, R.M.M.C\&H in Chidambaram, Cuddalore district of one year (From January to December 2018). After receiving the approval, data was carried out by a face-to-face interview method. Data was collected through the use of two tools. Tool I: A Structured - interview developed by the researcher and include socio-demographic data and diabetic profile related information. It includes age, gender, education, Body Mass Index (BMI), education status, occupation, personal history, duration, co-morbidities, and medication. Tool II: Quality Of Life Instrument for Indian Diabetes (QOLID) questionnaire is a recently developed diabetic specific instrument which is specially designed for Indian diabetic patients. The questionnaire was framed with the intention of reflecting the HRQOL and DSQOL comprising of 8 domains with 34 items which cover all aspects of QOL like Physical Health(PH), Physical Endurance(PE), General Health(GH), Treatment Satisfaction(TS), Mental Health(MH), Symptom Botherness (SB), Financial Worries(FW) and Diet Satisfaction(DS). Among the 8 domains, PH, PE, and GH are grouped in HRQOL whereas DS, TS, MH, SB, FW, and DS are related to DSQOL.

1. Physical Health: 6 Items measure the extent to which physical health interference with daily activities, including accomplishing less than wanted, limitations in the kind of activities or difficulty in performing activities.

2. Physical Endurance: 6 Items designed for physical activities measure how disease conditions interfere with daily activities in a decreased time spent on activities and not working or carefully or usual.

3. General Health: 4 Items measure overall health status.

4. Treatment Satisfaction: Measure 4 items related to satisfaction with the current treatment.

5. Symptom Botherness: Measure 3 items related to symptoms observed in diabetic condition like thirst, hunger, frequent urination.

6. Financial worries: Measure 6 items related to costs and expenditure towards diabetes management.

7. Mental Health: Measures 5 items of general mental health like how much satisfied as they for the support they got from others.

8. Diet Satisfaction: Measures 3 items related to how often they restrict or avoid the food of choice because of diabetes.

Data thus obtained was coded and entered into Microsoft Excel worksheet. This was analyzed using SPSS 22 version. Descriptive statistics like mean and standard deviation of QOL calculated. Data analysis was focused on descriptive statistics and correlation among the variables studied.

\section{Results}

Socio-demographic variables- Out of 100 subjects the majority of them, $45 \%$ belongs to age group 51-60 years and $25 \%$ belongs to $41-50$ years. $37 \%$ were males and $63 \%$ were females. Majority $35 \%$ was a primary school, majority of them around $45 \%$ were unemployed which include house wife, retired and those who are not working, $41 \%$ were semiskilled workers and $8 \%$ were skilled workers. Majority of them $49 \%$ belongs to lower socio-economic status according to BG Prasad 
Journal of Exercise Science \& Physiotherapy Vol. 15 No. 1 (January to June) 2019

ISSN: 0973-2020 (Print) I I OR Impact Factor $=6.502 \quad$ ISSN: 2454-6089 (Online)

scale of socio-economic status classification. In personal habits like alcohol or tobacco, chewing was present around $32 \%$ and $68 \%$ were unknown for personal history (Table 1).

Table 1. Mean \pm S.D of Frequency and Percentage of Socio-demographic variables

\begin{tabular}{|c|c|c|c|c|c|}
\hline Determinants & Variables & Frequency & Percentage & Mean & S.D \\
\hline $\begin{array}{l}\text { Age } \\
\text { group (years) }\end{array}$ & $\begin{array}{l}30-40 \\
41-50 \\
51-60 \\
61-70 \\
71-80\end{array}$ & $\begin{array}{c}5 \\
25 \\
45 \\
20 \\
5\end{array}$ & $\begin{array}{c}5.0 \\
25.0 \\
45.0 \\
20.0 \\
5.0\end{array}$ & 2.96 & 0.920 \\
\hline Gender & $\begin{array}{c}\text { Male } \\
\text { Female }\end{array}$ & $\begin{array}{l}37 \\
63 \\
\end{array}$ & $\begin{array}{l}37.0 \\
63.0 \\
\end{array}$ & 1.63 & 0.485 \\
\hline Education & $\begin{array}{c}\text { Illiterate } \\
\text { Primary } \\
\text { school } \\
\text { Middle } \\
\text { school } \\
\text { High school } \\
\text { Graduate }\end{array}$ & $\begin{array}{l}18 \\
35 \\
17 \\
18 \\
12\end{array}$ & $\begin{array}{l}18.0 \\
35.0 \\
17.0 \\
18.0 \\
12.0\end{array}$ & 2.71 & 1.289 \\
\hline Occupation & \begin{tabular}{|c|} 
Unemploym \\
ent \\
Housewife \\
Semi-skilled \\
Skilled
\end{tabular} & $\begin{array}{c}6 \\
45 \\
41 \\
8\end{array}$ & $\begin{array}{c}6.0 \\
45.0 \\
41.0 \\
8.0\end{array}$ & 1.56 & 0.641 \\
\hline $\begin{array}{l}\text { Socioeconomic } \\
\text { status }\end{array}$ & \begin{tabular}{|c|} 
Upper \\
middle class \\
Middle class \\
Lower \\
middle class \\
Lower class \\
\end{tabular} & $\begin{array}{c}4 \\
21 \\
\\
26 \\
49\end{array}$ & $\begin{array}{c}4.0 \\
21.0 \\
\\
26.0 \\
49.0 \\
\end{array}$ & 4.19 & 0.907 \\
\hline Personal history & $\begin{array}{c}\text { Nil } \\
\text { Present }\end{array}$ & $\begin{array}{l}68 \\
32\end{array}$ & $\begin{array}{l}68.0 \\
32.0 \\
\end{array}$ & 0.68 & 1.118 \\
\hline Marital status & $\begin{array}{c}\text { Widow } \\
\text { Married }\end{array}$ & $\begin{array}{l}18 \\
82\end{array}$ & $\begin{array}{l}18.0 \\
82.0\end{array}$ & 1.82 & 0.386 \\
\hline
\end{tabular}

Diabetic profile and associated co-morbidities- Out of 100, 51\% were having a family history of diabetes, $33 \%$ for $1-5$ years in duration and 6-10 years duration of diabetes. $49 \%$ of the subjects were overweight with BMI 25.0-29.9 and 43\% were obese with BMI 30 and over. $92 \%$ of subjects were with diet only while treated with oral hypoglycemicagents, $41 \%$ combined oral hypoglycemic and insulin. The co-morbidities were present in $78 \%$ of subjects (Table 2 ). 
Journal of Exercise Science \& Physiotherapy Vol. 15 No. 1 (January to June) 2019

ISSN: 0973-2020 (Print) $\quad \mathrm{I}_{2} \mathrm{OR}$ Impact Factor $=6.502 \quad$ ISSN: 2454-6089 (Online)

Table 2. Mean \pm S.D of Frequency and Percentage of Diabetic profile and associated co-morbidities

\begin{tabular}{|l|c|c|c|c|c|}
\hline Determinants & Variables & $\begin{array}{c}\text { Frequ } \\
\text { ency }\end{array}$ & $\begin{array}{c}\text { Percent } \\
\text { age }\end{array}$ & Mean & S.D \\
\hline \multirow{3}{*}{ Family history } & Yes & 51 & 51.0 & 1.51 & 0.50 \\
& No & 49 & 49.0 & & 2 \\
\hline \multirow{5}{*}{ Duration } & 1-5 years & 33 & 33.0 & & \\
& 6-10 years & 31 & 31.0 & & 1.12 \\
& 11-15 years & 24 & 24.0 & 2.20 & 8 \\
& 16-20 years & 7 & 7.0 & & \\
\hline \multirow{3}{*}{ Medication } & 21-25 years & 5 & 5.0 & & \\
& Oral & 92 & 92.0 & & 0.43 \\
& Insulin & 4 & 4.0 & 1.12 & 3 \\
\hline \multirow{3}{*}{ BMI } & Both & 4 & 4.0 & & 0.73 \\
& Normal & 22 & 22.0 & & 6 \\
\hline \multirow{3}{*}{ Co-morbidities } & Obese & 29 & 29.0 & & 6 \\
& Nil & 22 & 22.0 & & \multirow{2}{*}{1.78} \\
& Present & 78 & 78.0 & 1.92 & 5 \\
\hline
\end{tabular}

QOLID in type-2 diabetes mellitus subjects-The mean and standard deviation score of Physical health was $19.0 \pm 5.623$, Physical endurance $18.33 \pm 6.000$, General health $7.09 \pm 1.90$, Treatment satisfaction 12.45 \pm 3.27 , Symptom botherness 10.7 \pm 2.67 , Financial worries $13.44 \pm 2.98$, Mental health14.5 \pm 3.76 and Diet satisfaction $8.44 \pm 2.88$ (Table 3).

Table 3. Mean \pm S.D of Frequency and Percentage of Quality Of Life Instrument for Indian Diabetes (QOLID)

\begin{tabular}{|c|l|c|c|}
\hline S.No & Dimensions & Mean & S.D \\
\hline 1 & Physical health & 19.0 & 5.623 \\
\hline 2 & Physical endurance & 18.3 & 6.00 \\
\hline 3 & General health & 7.09 & 1.90 \\
\hline 4 & Treatment satisfaction & 12.45 & 3.27 \\
\hline 5 & Symptoms bothered & 10.7 & 2.67 \\
\hline 6 & Financial status & 13.44 & 2.98 \\
\hline 7 & Mental health & 14.5 & 3.76 \\
\hline 8 & Diet satisfaction & 8.44 & 2.88 \\
\hline
\end{tabular}

\section{Discussion}

Quality of life refers to the physical, psychological and social domains of health that are influenced by a person's experiences, beliefs, expectations and perceptions (Wild et. al., 2004). Diabetes has a strong influence on the QOL which has a multidimensional perception such as social, physical, and 


\section{Journal of Exercise Science \& Physiotherapy Vol. 15 No. 1 (January to June) 2019 ISSN: 0973-2020 (Print) $\quad \mathrm{I}_{2} \mathrm{OR}$ Impact Factor $=6.502 \quad$ ISSN: 2454-6089 (Online)}

role functioning, worries about the future, emotional and general well-being (Fayers and Machin 2007). Majorities of diabetes patients have negative emotional feelings such as frustration due to diabetes (Polonsky 2000).Type-2 diabetes has become one of the pivotal conditions in terms of morbidity and mortality and the prevalence of diabetes mellitus has been increasing worldwide over recent years. T2DM has rapidly become a global health problem due to rapidly mounting population growth, aging, urbanization, obesity and physical inactivity (Coffey et. al., 2002) ${ }^{(21)}$. "Sedentary behavior ", defined as engaging in activities at the resting level of energy expenditure, which includes sleeping, sitting, lying down, computer time and viewing television, also plays an important role in the etiology of type-2 diabetes (Pate et. al.,2008). Numerous demographic and psychosocial factors such as age, gender, alcohol consumption, control on blood sugar level,fatigue and psychological stress have been found to influence the quality of life (Lyrakos et. al., 2012). The present study comprising of 100 subjects, the majority of the 45\% belonged to age group 51-60 years, $37 \%$ were males and 63 were females. Majority of them $35 \%$ were primary school and most of the $45 \%$ was a housewife. Majority of them $49 \%$ belongs to lower socio-economic status. $80 \%$ were married. $68 \%$ of study subjects having an unknown for personal history. Type-2 diabetes is a chronic illness associated with high rates of co-morbidity and mortality. In the present study, the diabetic complication is more prevalence in $22 \%$ of study subjects. Visual impairment ranked first $(50 \%)$ followed by hypertension (27\%), peripheral neuropathy $(26 \%)$, ischemic heart disease $(5 \%)$ and dyslipidemia(6\%). These with two or more complications constituted $30 \%$ of study subjects in diabetic complications. The current study is correlated with the previous studies such as Thommasen et. al., observed the most prevalent diabetic complications were coronary artery disease $(16 \%)$, retinopathy(15\%),neuropathy(9\%) and nephropathy(6\%). The study concluded that people with diabetes experience significant impairment in their health-related quality of life; the presence of diabetic complications significantly affects HRQOL in type-2 diabetes patients (Thommasen and Zhang 2006). The current study in Body Mass Index (BMI), 49\% were overweight, 29\% obese. Joshi has described a typical Asian Indian Phenotype with a higher percent of body fat and increased waist to hip ratio for any given BMI which predisposes to diabetes and metabolic syndrome (Joshi 2003). The results of a recent study conducted in North India indicated that there was a strikingly high prevalence of abdominal obesity and generalized obesity as determined by body fat in type-2 diabetes (Vikram et. al., 2003). QOLID is a reliable, valid and sensitive tool for the assessment of the diabetic specific quality of life in Indian subjects. Further work is necessary to instrument across a wider socio-economic status and in community settings. Linguistic validation is also necessary to allow the administration in different languages to a larger proportion of patients (Nagpal et. al., 2010). According to this study, the mean score for QOLID questionnaire domain in physical health was 19.0, physical endurance 18.33, general health 7.09, treatment satisfaction 12.4, symptom botherness 10.7, financial worries 13.44 , mental health 14.5 and diet satisfaction 8.44. According to the physical domain, there is sample epidemiological evidence to demonstrate that physical inactivity as an independent risk factor is fueling the epidemic of type-2 diabetes, predominantly in urban areas. The recent Indian Council of Medical Research India Diabetes (ICMR -INDIA) study also reported that levels of physical inactivity were high $(55 \%)$ among Asian Indians. One of the important reasons for the low prevalence of diabetes in the Indian rural-based population could be that these individuals have a physically vigorous lifestyle (Anjana et. al., 2014). Misra et. al., (2001) reported that migration from rural areas to urban slums in metropolitan cities leads to obesity glucose intolerance and dyslipidemia (Misra et. al., 2001). Fiji says that among Indian men, the prevalence of diabetes was more than twice as high in those graded as sedentary or undertaking light activity as in those classified as performing moderate or heavy exercise (Taylor et. al., 1984). 


\section{Journal of Exercise Science \& Physiotherapy Vol. 15 No. 1 (January to June) 2019 ISSN: 0973-2020 (Print) $\quad \mathrm{I}_{2} \mathrm{OR}$ Impact Factor $=6.502 \quad$ ISSN: 2454-6089 (Online)}

In psychosocial domain, the present study many patients experience stress and coping with diabetes can affect the severity of disease directly through the pathophysiological process or indirectly through patient's perception of illness by deteriorating adherence to therapy and daily functioning. According to the bio-psychosocial model originally proposed by Engel, the mind and body are two important systems are interconnected. The model offers additional insights into how chronic illness such as diabetes can affect daily activities (Engel 1977). Polonsky and Brod et al reported that psychological resistance (PIR) represent a complex of beliefs about the meaning of insulin therapy, poor self- efficacy, concerning the skills needed for this lack of accurate information, the fear of unwanted effects and complications from insulin use and social stigma (Polonsky et. al., 2005). In this study, 4\% of diabetic patients on insulin treatment reported that anxiety symptoms related to self- injecting.

Recognition of Diabetes Related Distress (DD)-Peyrot et al have shown that most health providers of the countries studied are aware of the level of patient distress secondary to diabetes. Incomplete therapeutic adherence, reduced self-efficacy, negative attitudes towards treatment are the component of diabetes-related distress that can result in poor glycemic control.The influence of socio-demographic factors (age, gender, education level, socio-economic status, cultural, environment), as well as psychological 1 characteristics of individual and the presence of symptoms of depression, were significantly associated with DD and glycemic control (Peyrot et. al., 2005). The current study discussed distress may the most effective in type-2 diabetes mellitus patients. Many diabetic patients hesitate to talk to their therapist about emotional distress and prefer to report medical symptoms and complaints. Some patients spontaneously express their DD, often in terms of demoralization about their ability to manage their diabetes and an unwillingness or inability to engage in active self-management despite recognition of the need for change (Rubin 2007). The next to identify patients with DD would be asking questions about specific sources and intensity of distress (having troubled accepting diabetes, feeling of overwhelmed or burned out by the demand of diabetes management, getting support from family members and worrying about getting complications. The present study financial worries domain, the patient bears the excessive cost and the economic loss due to lost work days or lost economic opportunity. In general, the absence of a significant or credible social security system in India requires the patient to depend on family support. This means that if the breadwinner of the family suffers a chronic illness, it would have a significant effect on the whole family. It may force other non- working members to start work, often prematurely at lower wages, cut short education with long term financial consequences for them and the family. This study correlated by Tharkar et al observed that more than $60 \%$ of the low-income group had to borrow or mortgage property for their diabetes treatment costs and approximately $70-80 \%$ of the high-income group spent most of their personal savings on treatment (Tharkar et. al., 2010). The present study noted that a high proportion of housewives were at risk of developing diabetes. The probable reason for this is that housewives are not doing any other physical activity apart from their household work and are not involved in any other day-to-day exercises. Arora et al observed similar findings, with the highest prevalence in housewives among occupational groups in their study carried out urban Haryana (Arora et. al., 2010).

Dietary alterations- India, is urbanization and economic growth occurs, there are major deviations in diabetes in the dietary pattern which are influenced by the varied cultural and social customs. The major dietary changes that urbanization and affluence bring about are, the substitution of unrefined wheat, rice or millets by highly polished wheat or rice and increased intake of fat in higher income group. High-calorie intakes by high-income groups in India are largely due to high intakes of refined cereals and carbohydrates rather than fats and meat as in Europe and North America (Gopalan 2001). Finally, the majority of Indian studies have reported a lower prevalence of metabolic syndrome than found in the present study, ranging from the lower age (50-60 years) 


\section{Journal of Exercise Science \& Physiotherapy Vol. 15 No. 1 (January to June) 2019 ISSN: 0973-2020 (Print) I I OR Impact Factor $=6.502 \quad$ ISSN: 2454-6089 (Online)}

of study participants. Many studies have evidenced that metabolic syndrome increases with age, and is more prevalent among smokers, consumers of alcohol and those who undertake less physical activity.

\section{Conclusion}

This study observed Physical component was affected in diabetic persons. The study concluded that patients with type-2 diabetes mellitus had relatively impact on health-related quality of life (Physical health, Physical endurance\& General health)domains and unsubstantial in diabetesspecific quality of life domains. Understanding the effect of diabetes on QOL is important for the day-to-day management and also for public health policy initiatives in order to improve the QOL and health outcomes of those with diabetes.

Patient Education Program: The objectives of health education are to support informed decisionmaking, problem-solving, active collaboration with the health education team, and self-care behaviors as well as to improve clinical outcomes, QOL, and health status.

\section{Acknowledgment}

First and foremost, I would like to thank GOD for his grace and great blessings. I wish to express my sincere thanks to Professor and Head of the Department, Physical Medicine\& Rehabilitation Dr. V.K MOHANDAS KURUP, for his valuable suggestions. I also offer my sincere thanks to Dr. T.JAYSREE, Professor, Division of Community Medicine and Mr. A.V SIVAKUMAR, Lecturer in Physiotherapy, Division of P.M.R, R.M.M.C\&H for valuable suggestions and empower our knowledge and for his encouragement. We are thanks to all the PATIENTS who participated in the study. I express my special heartfelt thanks to my PARENTS and friends who helped a lot for successful completion of this research.

\section{References}

Anjana R.M., Pradeepa R., Das A.K., Deepa M., Bhansali A., et al. 2014. ICMR-INDIAB Collaborative study group. Physical activity and inactivity patterns in India-results from the ICMR-INDIAB study phase1 (ICMR-INDIAB-5). Int J Behav Nutr Phys Act.;11(1):26.doi:10.1186/1479-5868-11-26.

Arora V., Singh M.J., Khanna P., Goyal N., Kumar N., Singh M. 2010.Prevalence of diabetes in urban Haryana. Australas Med J.; 3 (8):488-494.

Chyun D.A., Melkus G.D., et al. 2006.The association of Psychological factors, physical activity, neuropathy and QOL in type-2 diabetes.Biological Research for Nursing;7(4):279-88.

Coffey J.T., Brandle M., Zhou H., Marriott D., Burke R., Tabaei B.P. et al.2002.Valuing Health-Related Quality of Life in Diabetes. Diabetes Care.; 25:2238-43.

Engel G.L. 1977.The need for a new Medicinal model: challenge for biomedicine. Science; 196(4286):129136.

Fayers P.M., and Machin D.2007. QOL: The assessment, analysis, and interpretation of patient-related outcomes. $2^{\text {nd }}$ ed.west Sussex: John Wiley \& Sons.

Gopalan C. 2001. Rising incidence of obesity, coronary heart disease and diabetes in the Indian urban middle class. The possible role of genetic and environmental factors. World Rev Nutri Diet;90: 127-143 .

Hub: 2003.Sedentary lifestyle and risk of obesity and type-2 diabetes; Lipids; 38(2): 103-108.

International Diabetes Federation. The Diabetes Atlas, $7^{\text {th }}$ edn. Brussels: International Diabetes Federation,2009.

Joshi S.R. 2003.Metabolic syndrome -emerging clusters of the Indian phenotype J. Assoc Physicians India;51:445-446.

King H., Aubert, Herman W.H. 1998. Global burden of diabetes, 1995-2025: Prevalence, numerical estimates, and projections. Diabetes care; (21):1414-1431.

Kohai Kaku . Pathophysiology of type-2 diabetes and its treatment policy. NMAJ 53(1):41-46,2010.

Lyrakos G., Hattziagelaki E., Spinaris B., Damigos D., Spyropoulos I., Kostopanagiotou G.2012.The comparison of fatigue between patients with diabetes mellitus, psychiatric outpatients and general population in Greece.European Psychiatry.;27(suppl):1

Misra A.,Pandey R.M., Rama Devi.J.,et al. 2001.High Prevalence of diabetes, obesity, and dyslipidemia in urban slum population in northern India. Int J Obes;25:1-8.

Nagpal Kumar A., Kakar S., Bhartia A. 2010. The development of Quality of life Instrument for Indian Diabetes patients. (QOLID) : A validation and reliability study in Middle and higher income groups. J Assoc Physicians India.; 58:295-304. 


\section{Journal of Exercise Science \& Physiotherapy Vol. 15 No. 1 (January to June) 2019 \\ ISSN: 0973-2020 (Print) I I OR Impact Factor =6.502 ISSN: 2454-6089 (Online)}

Narayanan K., Gregg E.W., Fagot-Campagna A., Engelgau M.M., Vinicor F. 2000. Diabetes- A Common, growing, serious, costly and potentially preventable public health problem. Diabetes Res Clin Pract;50 (Suppl 2) :S77-84.

Olokoba A.B. and Obateru O.A. 2012.Type-2 diabetes Mellitus : a review of current trends; Oman MedJ;27(4):269-73,

Pate R.R.,O’Neill J.R., Lobelo F. 2008.The evolving definition of "sedentary". Exerc Sport Sci Rev.;36(4):173-8.doi:10.1097/JES.0b013e3181877d1a.

Peyrot M., Lauritzen T., Snoek F.J., Mathews D.R., Skoulund S.E. 2005.Psychological problems and barriers to improving diabetes management results of the cross-national Diabetes Attitudes, Wishes and Need and study.Diabet Med; 22(10) :1379-85.

Polonsky W.H., Fisher L., Gusman S., et al.2005.Psychological insulin resistance in patients with type-2 diabetes: the scope of the problem Diabetes care;28(10): 2543-5.

Polonsky W.H. 2000.Understanding and Assessing Diabetes-specific QOL. Diabetes Spectrum.;13(1):36-41.

Richard R.Rubin and Mark Peyrot. 1999.Diabetes/Metabolism Research and Reviews;15;205-218

Rubin R.R. 2007. Behavioral and Psychosocial interventions in Diabetes: A Conceptual review. Diabetes care; 30(10):2433-2440.

Tang W.L., Wang Y.M., D.U. W.M., Chang N.N., Chen B.Y. 2006. Assessment of QOL and relevant factors in elderly diabetic patients in the Shanghai community.Pharmcoepdemiol drug saf.; 15(2):123-30.

Taylor R., Ram P., Zimmer P., et al. 1984. Physical activity and prevalence of diabetes in Melanesian and Indian men in Fiji. Diabetologia;27:578-582.

Testa M.A. and Simonson D.C. Assessment of quality of life outcomes. N.Engl J.Med. 1996;334: 835-40.

Tharkar S., Devarajan A., Kumpatla S.2010. The socio-economics of diabetes from a developingcountry: used cost of illness study, Diabetes Res, Clin. Pract 89(3) ,334-340.

Thommasen H.T. and Zhang W. 2006. Health-related quality of life and type 2 diabetes: a study of people living in the Bella Coola Valley.BCM J.;48(6):272-8.

Unnikrishnan R., Anjana R.M. Mohan V. 2014. Diabetes in South Asians: is the phenotype different? Diabetes ;63 (1): 53-5 DOI:10.2337/db 13-1592

Vikram N.K., Misra A., Pandey R.M. et al. 2003.Anthropometry and body composition in Northern Asian Indian patients with type-2 diabetes. ROC curve analysis of BMI \& body fat. Diabetes Nutr Metab;16:32-40.

Wandell P.E. 2005.QOL of patients with diabetes mellitus.An overview of research in primary health care in the Nordic countries Scand J Primary Health care.;23(2):68-74.

Wang X., Chen J., Liu X. et al. 2017. Identifying pattern of lifestyle behaviors among people with type-2 diabetes in Tianjin, China: a latent class analysis: Diabetes Ther; 8(60,1379-1392.

Wild S., Roglic G., Green A., King H. .2004. Global prevalence of diabetes: estimates for the year 2000 and projections for 2030.Diabetes Care;27:1047-53.

Wild S., Roglic G., Green A., Sicree R., King H. 2004. Global prevalence of diabetes: estimates for the year 2000 and projections for 2030. Diabetes care; 27(5): 1047-53.

World Health Organization. Definition, diagnosis and classification of diabetes mellitus and its complications.1999(WHO/NCD/NCS/99.2;htpp://://apps.who.int/iris/bitstream/10665/66040/1/WH O-NCD-NCS 99.2pdf,accessed 1 March 2016).

World Health Organization. 2012.Global Status Report on Non-communicable Diseases 2014. Geneva: WHO.

Zimmet P., Alberti K.G., and Shaw. 2001. Global and societal implications of the diabetes epidemic. Nature; 414: 782-787.

Conflict of Interest: None declared 